\title{
قناة السويس ويوميات التأميم
}

\section{عرض \\ ايمان صلاح الدين}

كبير باحثين بدار الكتب و الوثائق القومية

من القضايا القديمة وكان له عامود أسبوعي فى صحيفة العربي الناصرية منذ إنشائها حتى وفاته، ومجلة الوعي العربي أيضًا.

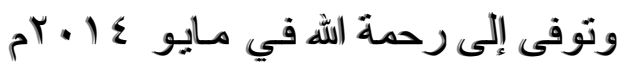

$$
\begin{aligned}
& \text { بالقاهرة مساء يوم الجمعة. } \\
& \text { ينقسم الكتاب إلى فصلين :- }
\end{aligned}
$$

ـ الفصل الأول ينقسم إلى النقاط التالية. 1 إلقناة بين الجغر افيا و التاريخ r ـ فكرة حفر القناة rـ ــ من السويس إلى الاسكندرية

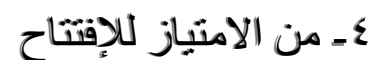

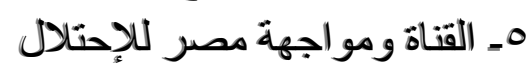
ـ الفصل الثانى بعنوان من يوميات معركة التأميهر.

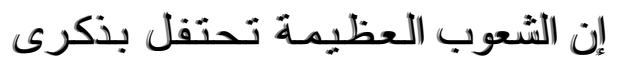

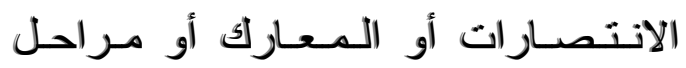

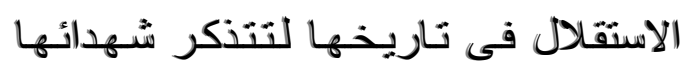
وأبطلالها الذين صنع فـاروا المجد وأيضًا

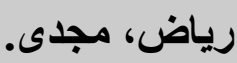

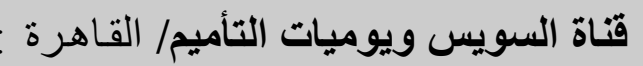

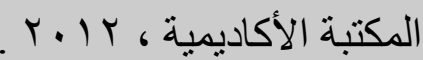
( يشتمل على ارجاعات ببليوجر افية.

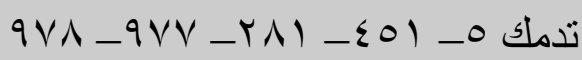
المؤلف فى سطور : المؤلف هو مجدى محمد رياض دوئ دويدار



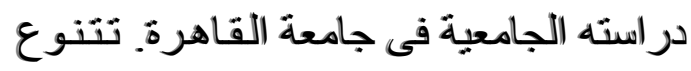

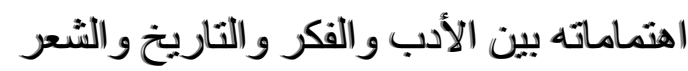

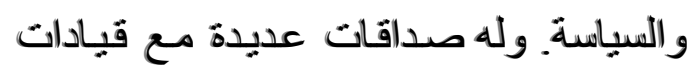
ناصرية فى اليمن والوطن العربي الكبير.

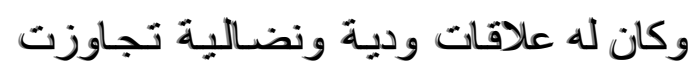

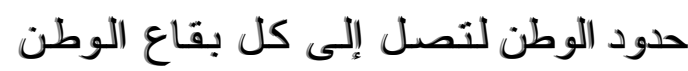

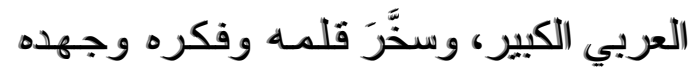

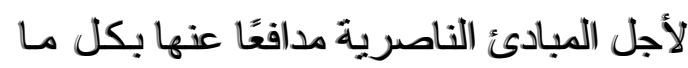
أوتي من قوة.

زار اليمن مرتين بدعوة من التنظيم

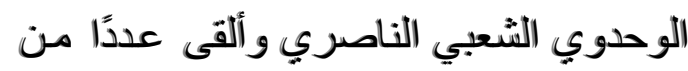

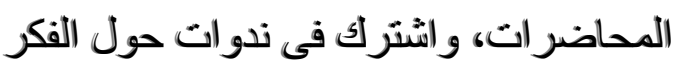

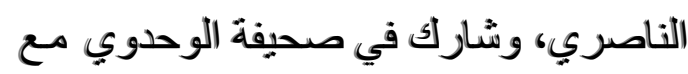

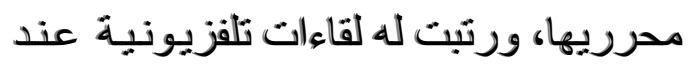

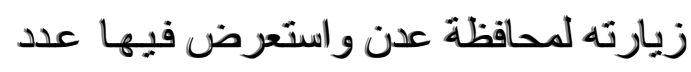


• إنها محاولة البشر لاستثمـار الموقع وتطويره (أي الجهد الحضاري الأي يعيد تشكيل الواقع و الموقع ).

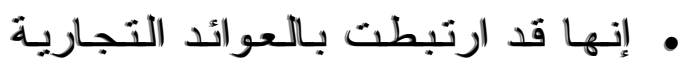
و الاقتصادية. • إنها اندمجت مع ضرورات الأمن القومي ورسم الحدود وصد الهجمـات المغيرة

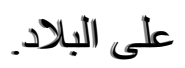

• وفى سبيل ذلك دفع الثعب المصري الثرد.



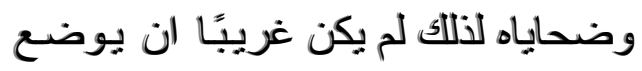
الجلاء وتأميم القتاة فى بوتقة واحدة في في

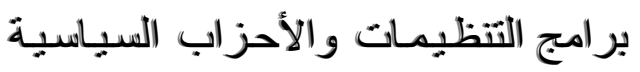
المصرية من عشرينيات القرن المـاضي أي قيل الثورة وقيل أن يتخذ عبد التـاصر

$$
\text { قر اره بعشر ات السنين. }
$$

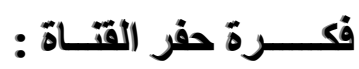

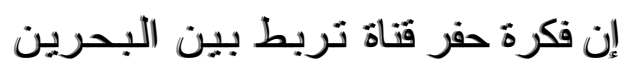

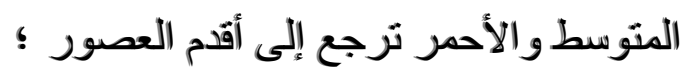

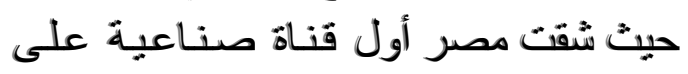
وجه الأرض، وحفر الفراعنة قناة تربط بين

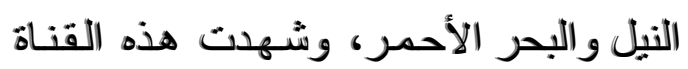

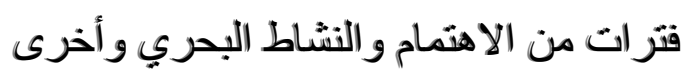

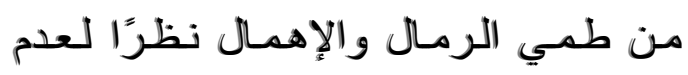
الاهتمام والخمول العسكرى والبحري

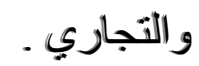

قام سنوسرت الثالث من الأسرة الثانية

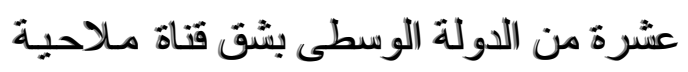
تربط البحرين المتوسط والأحمر عند الأند


باسم قناة سيزوستريس (سيزوستريس هو
لتسترجع الأكريات للتعليم و الـعبر وليس



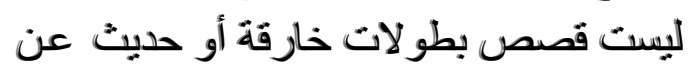
قوة الاتتصار أو صلابة المواقف - رغم أن لفوان تفاصيل هذا الموضوع تدعو للفخر - وهي ليست مجرد إيراز للدور فرد وتضخيم أو الو تون بلورة تأثير دور الزعامة السياسية. وحرب السويس لم تحدث فجأة ولم تكن وليدة اللحظات والنضـالات التى سبقتهات مباثرة ولكن تمتد لتصل إلى اللحظدات الأولى التى بدأت قوات الاحتلال اليريطاني

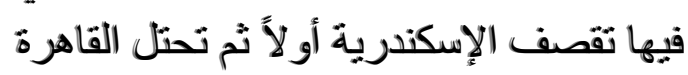


القناة بتاريخ النضـال من أجل التحرير

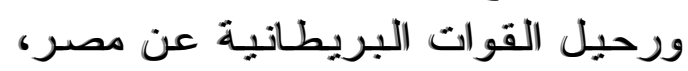
وتداخل تحرير الأرض مـع تحرير القناة

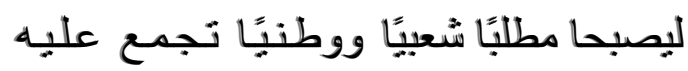

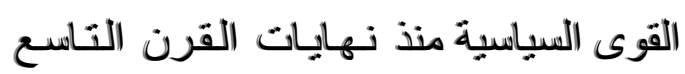
عشر وحتى متتصف القرن العشرين . وقبل الحديث عن تأميم القتاة يمكن القول إن قصة وتاريخ حفر قناة السويس حلم راود المدئ المصريين لآلاف من السنين بصورها المختلفة من عهد الفر اعنة مرورًا بالعصور والإسلاميـة منها ووصو لاً إلى العصور الحديثة وخروج قناة السويس إلى الى الوجود

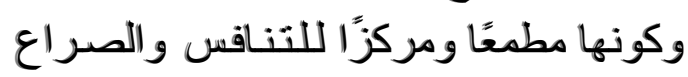
بين القوى الاستعمارية ؛ فقد كانت الطريق القديق

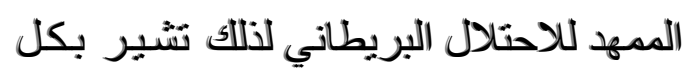
وضوح إلى حقائق هامة ومصيرية وهي :


وموقع مصر. 
الجمال للسويس لمطاردة سفن أرنولد حاكم

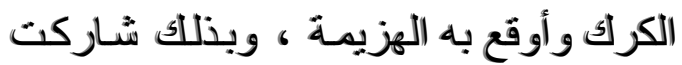

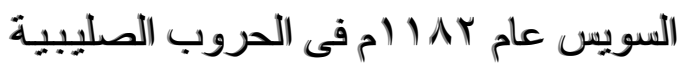

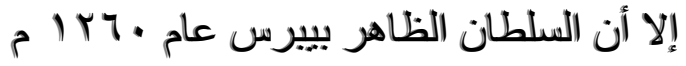
قام بترميم قلعة السويس وحفر بئر بجوار الطبر بار

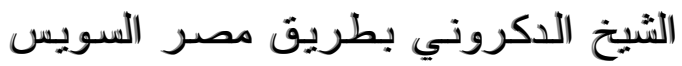

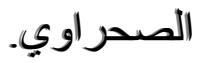
من السويس إلى الإسكندرية :

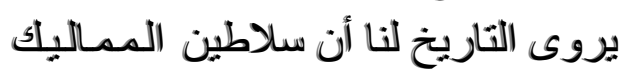
حكموا مصر و الثشام فى نهايـة العصور

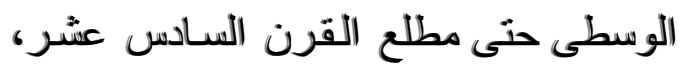

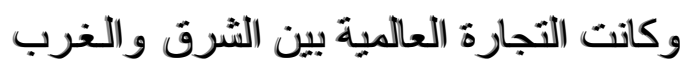
في العصور الوسطى تسلك عدة طرق بريـة

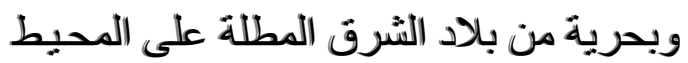
الهندي حتى تصل إلى الأسواق الأوروبية، وان أغلب هذه التجارة كاتت تمر عبر طريق التئ التافي البحر الأحمر إلى السويس، ثم إلى القاهرة بالقو اقل ومنها على ظـهر السفن في فرع الإنى

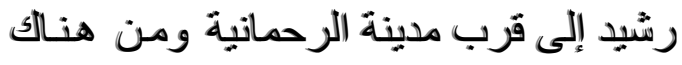
إلى الإسكندرية إما بالملاحة فى تر عة كانت تصل ما بين النيل والإسكتدرية أو على ظهر الإنى

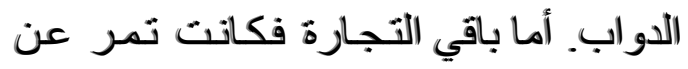

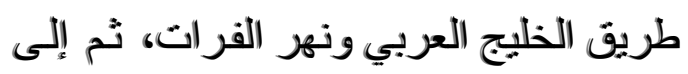

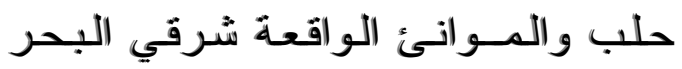
المتوسط ، والى موانئ مصر و الثـام،

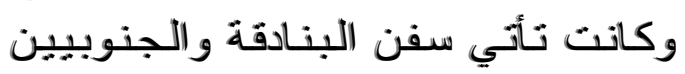

وغير هم فتتقل سلع التجارة إلى اوروبا. وشهدت مدينة الإسكندرية نشاطًا تجاريًا ملحوظًا فى النصف الثاني من القرن

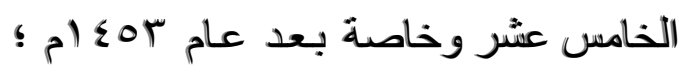
حيث كاتت معظم إيرادات الحكومـة
نفسـه الملك سنوسرت الثالث ولكن تم تحريف اسمه على يد النوبينين). فبعد أن تمت حملاته الحربية وانتصـار اتـه فى بـلاد

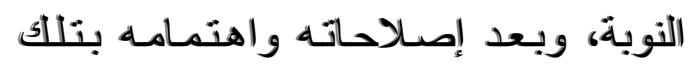

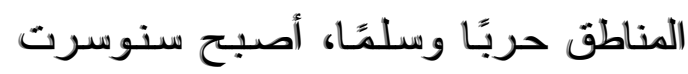
واحدًا من بين الآلهة الآين يعدون أربابًا لبلاد

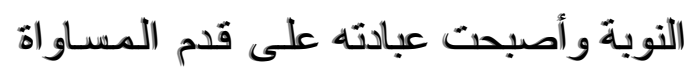
مع عبادة الآلهة في عهد تحتمس الثالث وفى وفى الثى عام شق القناة تحركت القوات بأمر القرعون لتطارد أعداء مصر من ممـالك الثرق، الثرق،

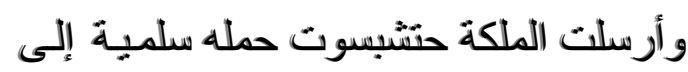

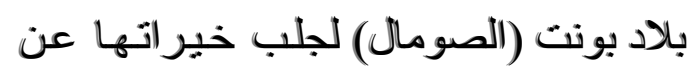
طريق ميناء السويس، وكانت حملات سليمة

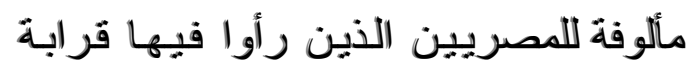

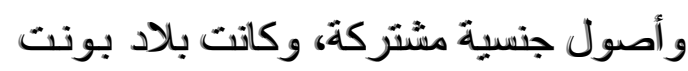
تسمى في الأدب المصري بالأرض المقدسة (أرض الإله)، وقررت حتشّبسوت إعادة شث الأن

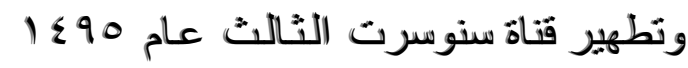

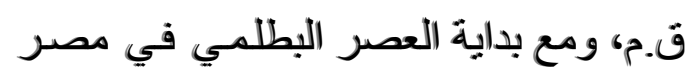
سبr ق.م انسحب برزخ السويس إلى منطقة



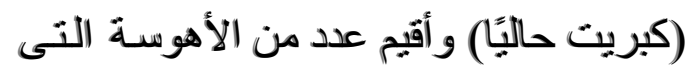

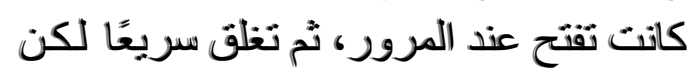
هذه القتوات هجرث فى أواخر عهد البطالمـة واستعيض عنها بالطريق البري.

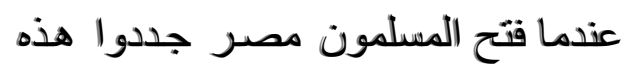

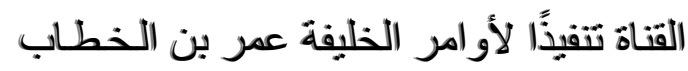

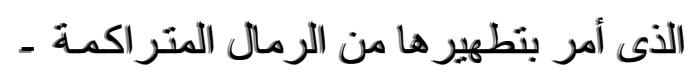

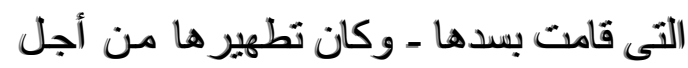

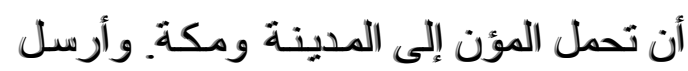
الملك العادل الأيوبي اسطولاً على ظهر الهر 
وبينما استمرت المواجهات والمعاهدات كانت أحلام شق القناة تر اود الجميع فنقفز تارة إلى السطح وأخرى تعود إلى قاع النسيان بسبب الأحداث أو عجز الإمكانيات أو سوء التقدير ات و الدر اسات. من الامتياز إلى الافتتاح :

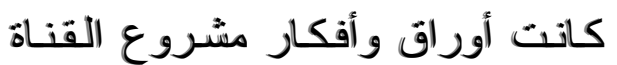
تثقلب مع تقلب الستين إلا أنها توقفت قليـلاً في أثناء الحملة القرنسية عند سطور تبرز زيارة نايليون بونابرت للسويس في

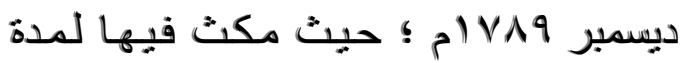
عثرة أيام وذهب إلى عيون موسىى ليدرس مع علمـائه فكرة ربط البحرين الأحمر و المتوسط ولكن مهندس الحملة القرنسيـة (لابيير) وقع فى نفس التقدير ات السـابقة والخاطئة بأن البحر الاحمر مستوى مياهـه أعلى من مستوى مياه اليحر المتوسط فتم

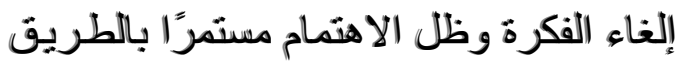
التجـاري بين البحرين وظل التطوير

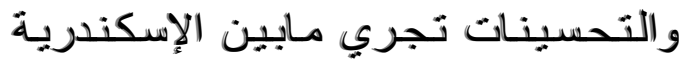
و السويس فقد حصل الضـابط الإنجليزي الإنيانيل (توماس واجهون) عام بr M ا م على امتياز تيسير قو اقل بين السويس والقاهرة باستخدام عربات تجر ها الخيول، وبعد عدة سنو ات قام عباس باثـا الأول برصف طريق السويس

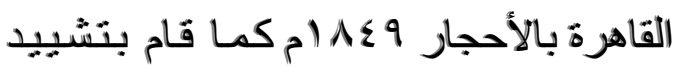
قصر عند الكيلو • T سمى (الييت الأبيض)

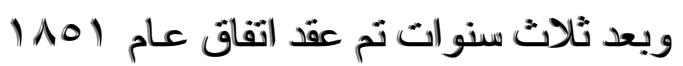
مع روبرت ستيفنسون مخترع القاطرة

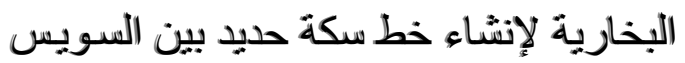
والإسكندرية وتم استكماله فى عهد سعيد لإنه
المملوكية من الجمارك وشكلت الإسكندريـة المحطة الرئيسية للحجاج المسيحيين الو افدين

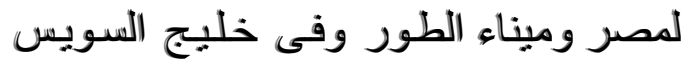
الذى مثل المحطة الرئيسيـة للحجباج المسيحيين الو افدين من دير سانت كاترين. و عندما اكتشف اللرتغاليين طريق رأس دأس الرجاء الصالح فى نهايـة القرن الخـامس عشر وبداية القرن السادس عشر الميلاديين تغيرت معالم ومو اقع حركة التجارة العالمية، ولم تعد مصر والإسكندرية قلب هذه التجـارة وعم الخراب البلاد نتيجة لتدهور الأحوال

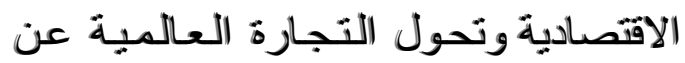
مصر و عالم البحر المتوسط، وفى محاولة

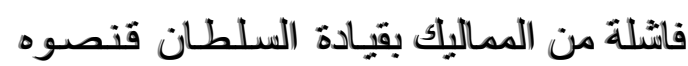

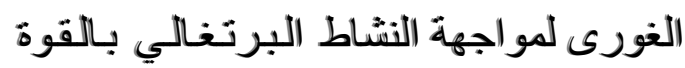

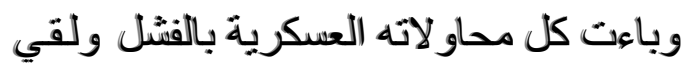
الهزيمة من العثمانيين. وحكم العثمانيين مصر بقيادة سليم الأول الذي عمل على على الذي إنعاش الحركة التجارية فى مصر آنذاك عبر

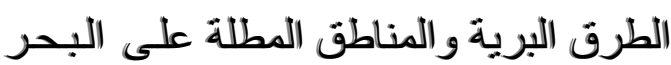

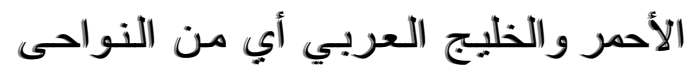
الواقعة على شرقي مصر وجنوبها وغربها ؛

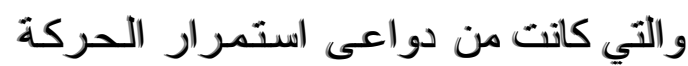

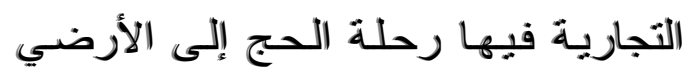
المقدة في الحجاز ؛ حيث كان الحجـاج

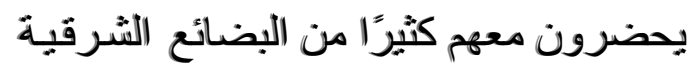

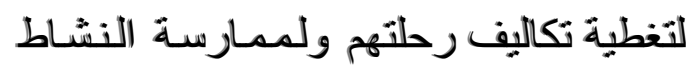
التجاري أيضًا و عقد الاتقاقيات و المعاهدات

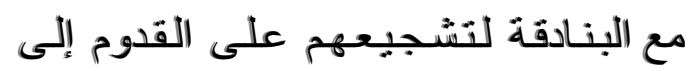
الإسكتدرية بسفنهم وبضـائعهم ومباشترة نشاطهم التجاري. 
وانقتاحاته وراء هذا الرواج لكن خلفائه

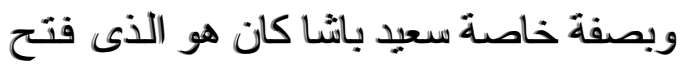
الباب على مصر اعيه للأجانب و المغامرين وأغدق عليهم التسهيلات والقروض من جهة وأتاح لهح فرص الثراء والنه والثب وقبول مشرو عاتهم الغََّّ منها و السمين، وقتح شهية الجميع لرواج القطن المصري مـع تدهور

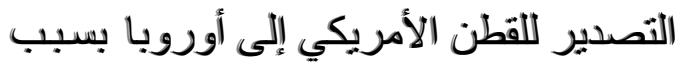

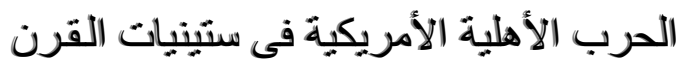
التاسع عشر من جهة أخرى. ورغم انتشار الفكرة لاى جهات عدئ عديدة حول إمكانية شق قناة بين البحر الأحمر و المتوسط إلا ان المهندس فرديناند ديليسبس فيس المبن

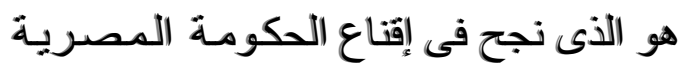
بفكرة إنشاء القناة و اقنع الو الي سعيد باثُا بأن



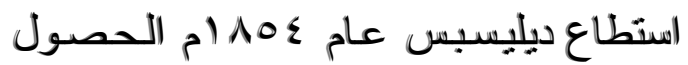
على عقد امتياز يإنشاء الثركة العالمية لقناة

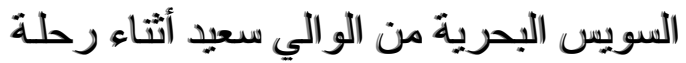
خيل بين القاهرة والإسكندرية استمرت لأيسام

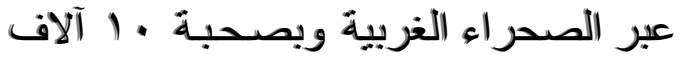
جنديًا بمداقعهم وخيو لهم وكانت العودة إلى اهلى

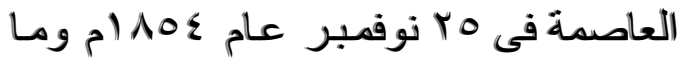

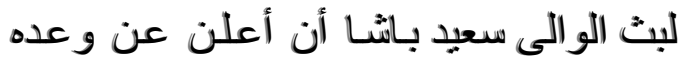
لديليسبس في صيغة فرمان فى • ب نوفمبر واثنمل هذا القرمان على اثني عشر بنداً كلها تحتوي على تفريط بلا حدود ومكاسب للغير بلا منطق أو ضرورة منهـا الحصول

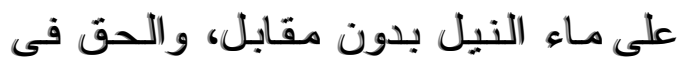

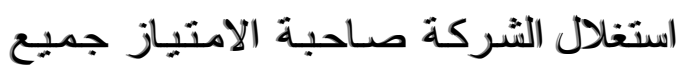

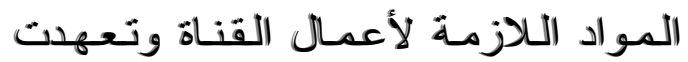

بانشا وكان التلغر اف الكهربائي قد حل عام

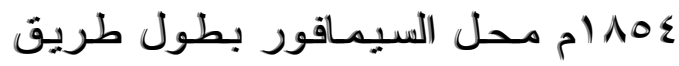
الإسكندرية والقاهرة كما أنشأ سعيد خط آخر

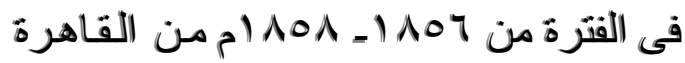
إلى السويس واستكمل بذللك الاتصـال البري بين أوروبا والهند، ورجحت بريطانيا هذا الطريق وفضلته على مشروع حفر قناة وروناة السويس. - الطزي. إن مشروع حفر قناة بين البحرين الأحمر و الأيضض كان يدور فى خلا الكثيرين ولكن كانت هناك مصالح وطموحات و أفكار تأججت بالاهتمام والجدل حول المشروع فحضرث بعثنات إلى مصر من أوروبـا

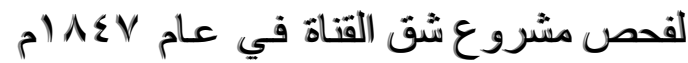

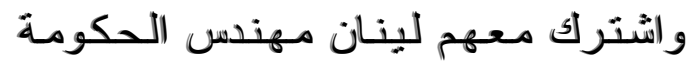

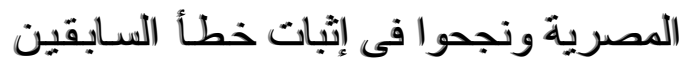
وأن اليحرين فى مستوى واحد ولكن محمد

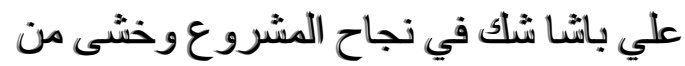

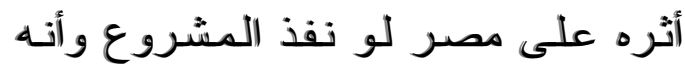
سيجعل مصر مطمعًا للساعين إلى السيطرة على شريان المواصلات العالمية . دارت عجلـة الـزمـان وعـاد الـرواج التجاري و التبادل وازدهر دور الإسكندريـة كميناء ومدينة جاذبـة للاستثمـار والتجار الاردي و السفن و اتجهت الأنظار إلى السويس كميناء ونقطلة وصل لطريق المـلاحـة بـالبحر البحر المتوسط والموصل إلى البحر الأحمر والهند. وكانت شركة مخاطرة السويس قد تم

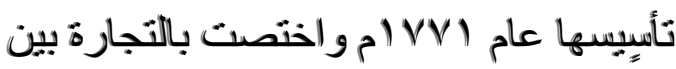

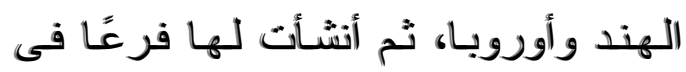
السويس، توقفت إصلاحسات محمد علي 
للمشروع وإعادة الأراضى الأخرى للحكومة

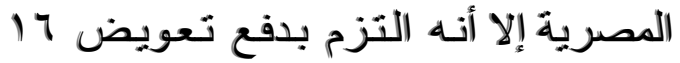
مليون فرنلك للشركة عن بند ترعة المياه

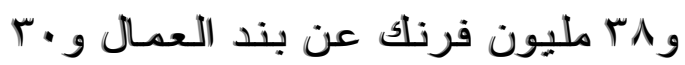
مليون فرنك عن الأر اضى المعادة.

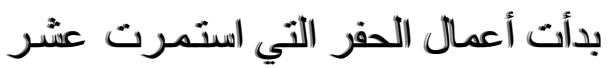

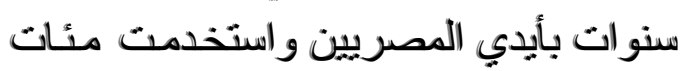
الآلاف من الأيدى العاملة بالسخرة فى البناء الئاء

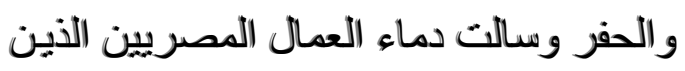

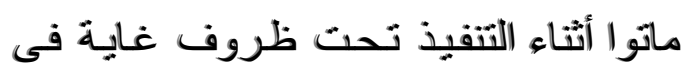
الصعوبة وقد مات حوالى · r ا ألف مصريًا من الفـلاحين والعاملين بـالسخرة مات بسيب

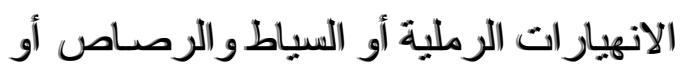

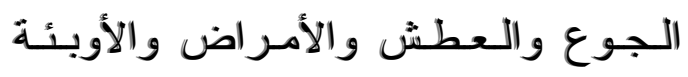

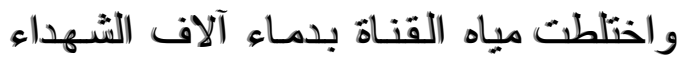

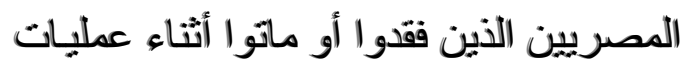
الحفر.

تم الافتتاح الكيير بـالانتهاء من حفر القناة في حفل مهيب أقامه الخديوني

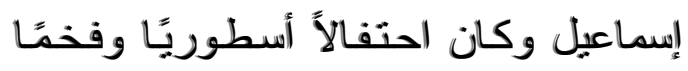
وأنقق المبالغ الباهظة التى قدر ها المؤرخون التِ

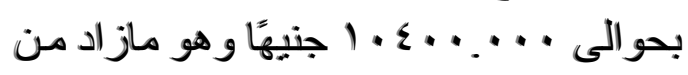


القناة، وأغرق إسماعيل خديوي مصر البـلاد

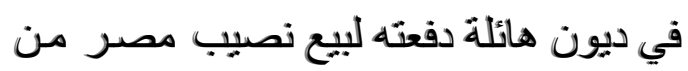

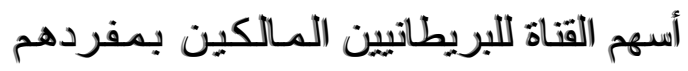
للنصيب الأكبر فى أسهم قناة السويس وفي الني عام T1 ال م حصل على لقب خديوي ومنـه

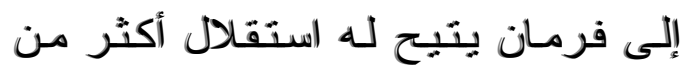

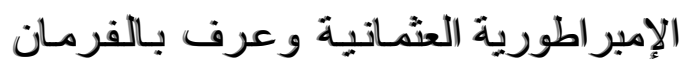

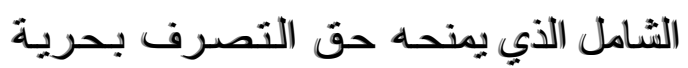

الحكومة المصرية بتقديم كل معونة فى سبيل

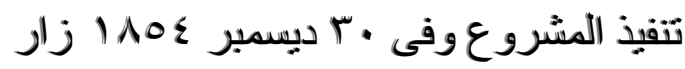
ديلسيس السويس لدر اسة مدى صلاحية ميناء

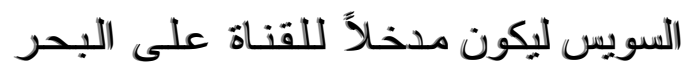

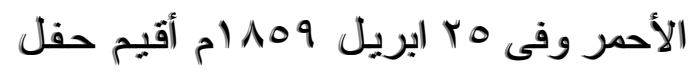
بسيط فى بورسعيد إيذانًا بالحفر. وطرح الاكتتاب فى أسهمح الشركة العالمية لقتاة السويس البحريسة وكان عدد الإدئ الأسهـم · .ع ألف، لم تزيد عدد الأسـهم

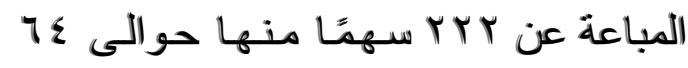

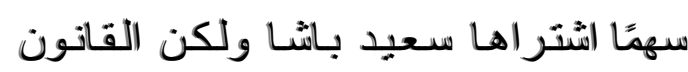

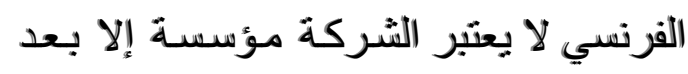



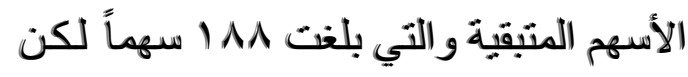

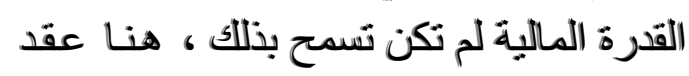

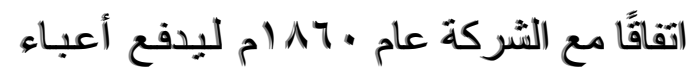

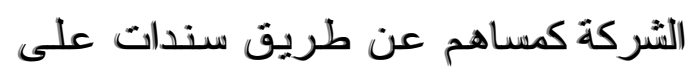

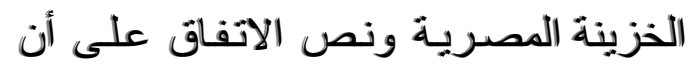

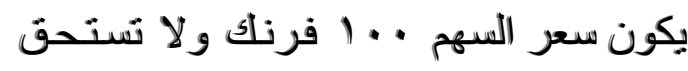

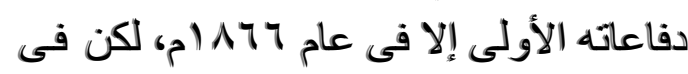

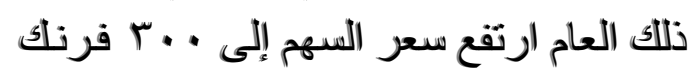


قرنك إلى عه مليون فرنلك.

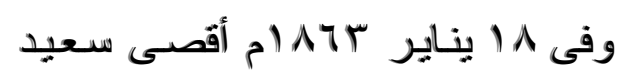

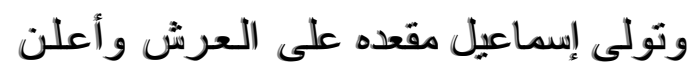

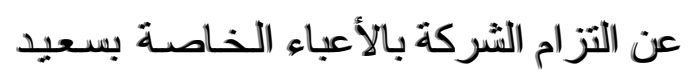

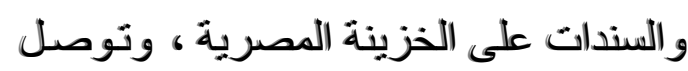

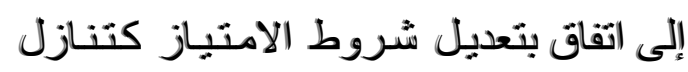
الثركة عن كل حق في ترعة المياه العذيـة، وإبطال حق الثركة فى المطالبة بتقديم العمال المصريين وتحديد الأراضى اللازمـة 
القتاة ومواجهة مصر للاحتلال :

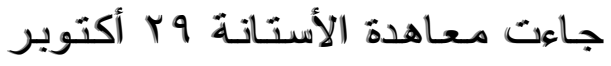

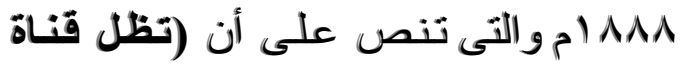

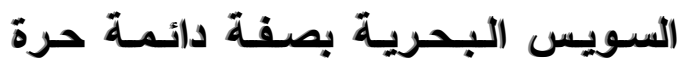

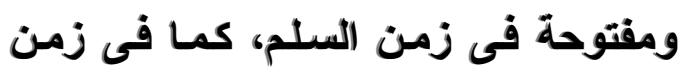
الحرب لجميع السفن التجاريـة والحربية

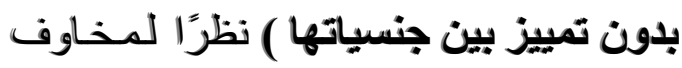

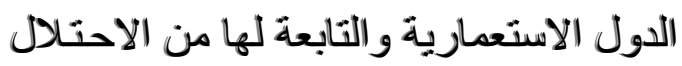
البريطاتي لمصر، وكانت الدول التى أبرمت الآتهات

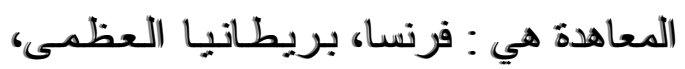

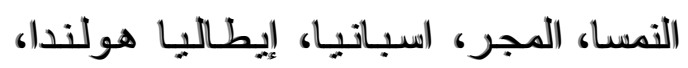
روسيا، تركيا نيابـة عن مصر. ومنذ ذلك الك الك الكانيا،

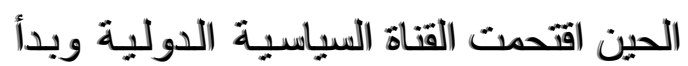
الارتباط والتداخل بين الاحتلال وشركة قناة السويس يفرض تفسه على الحركة الوطنيـة المصرية . ن الموبن

نجحت شركة قناة السويس في إقناع

السير الدون جورست قتصل بريطانيا العام

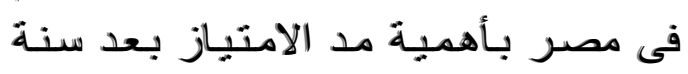

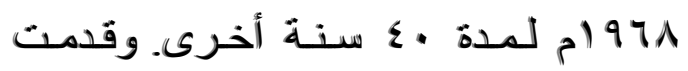

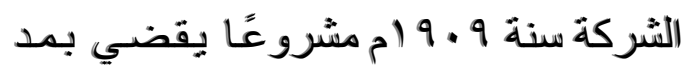

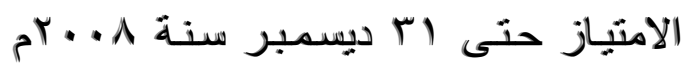
مقابل حصول مصر ابتداء من أول يناير

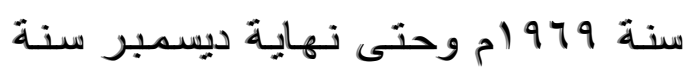

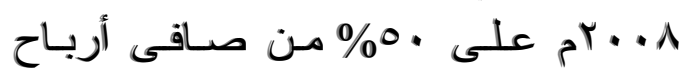

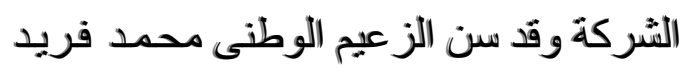

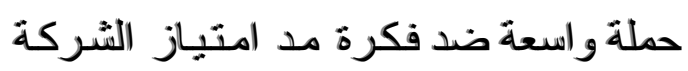

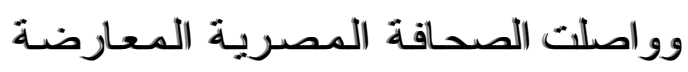
للمشروع خاصـة جريدة اللاواء، وجريدة

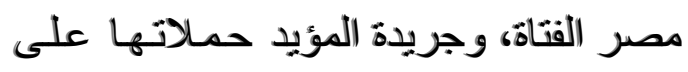
رفض المشروع وطـالبت بعقد جمعيـة وعلد
تامة في شُؤون الدولة ماعدا عقد المعاهدات السياسية وكذلك حق التمثيل الدبلومـاسي، التهي،

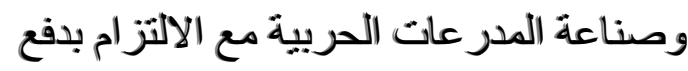
الجزية السنوية. وهى V0 ألف جنيهًا الحكم الحئم الخديوى توفيق و عندما تولى الحكم من ون الجن

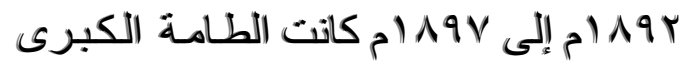
حيث تمث تصفية الوجود المصري داخل

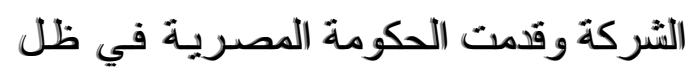

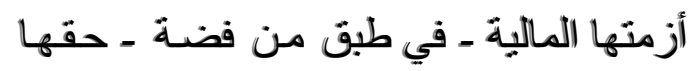


جي A .... .

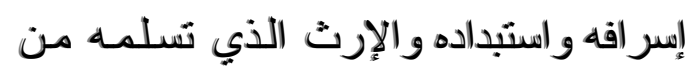

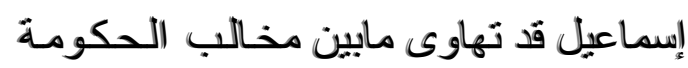
الأوروبية وقك الحكومـة البريطـانية التي تركزت أطسـاعها نـحو مصـر والقنـاة باعتبار ها مفتاح السيطرة في اليحر المتوسط اطيط

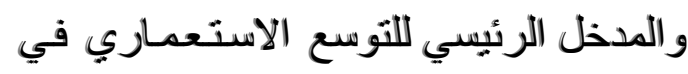

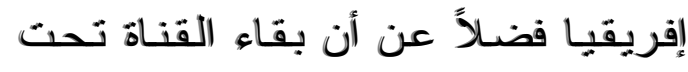
السيطرة الفرنسية أمر لم يكن يطمئن انجلترا

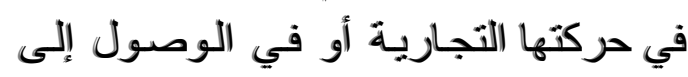

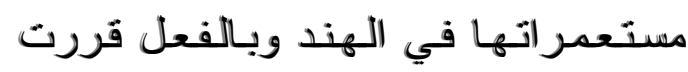

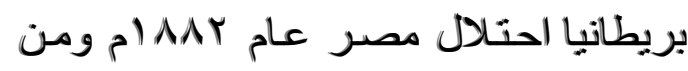
سخريات القدر أنهم لم يستطيعوا الدخول إلى دئ

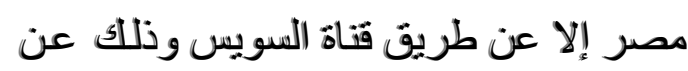

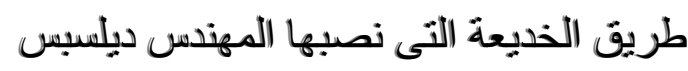

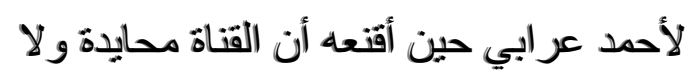



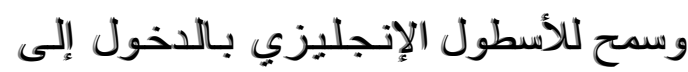

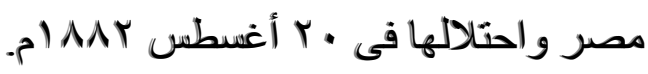


الشركة وقد عادت الثركة إلى بـاريس بعد انتهاء الحرب وهذا يعني إصـرار الثـركة

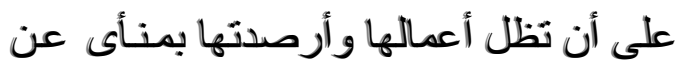

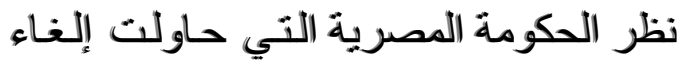

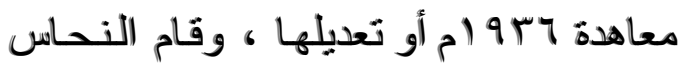
باثنا رئيس الحكومـة المصريـة بـإلغناء المعاهدة في أكتوبر 901 (م التي ظلت تربط



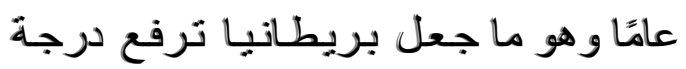
استعدادها في منطقة القناة.

كان هذا هو الوضع العام للعلاقات بين

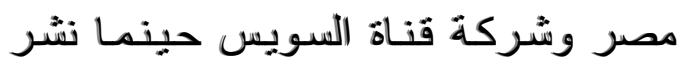
الدكتور مصطفى الحفتاوي الجزء الأول من

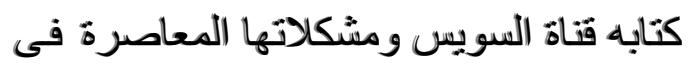

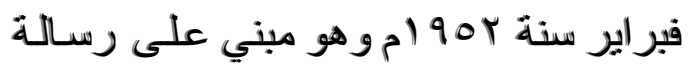
الاكتور اه التي أعدها و استعمل في كتابتها وثائق الثركة المحفوظة في باريس و أكد في كتابه أن القناة قد لازمت الاستعمار وسـارت معه جنبًا إلى جنب وطالب بإنقاذ الشرق كله الثهار من الاستعمار بالتمـهيد لتسلـم القناة سنـة فئة

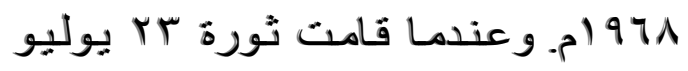


انجلتر ا بجلاء قواتها عن منطقة وقاعدة قناة السوس وأدث تللك المطالبات المصريـة إنى إلى ألى

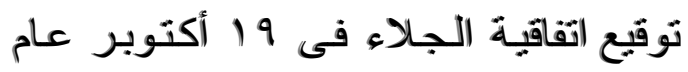

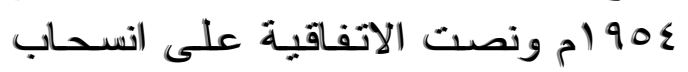
القوات البريطـانيـة على مراحل خـلال

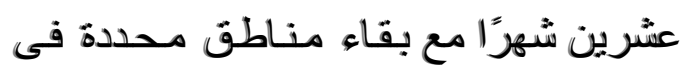

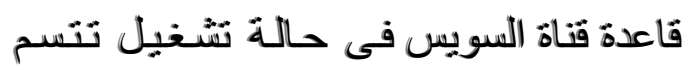
بالكفاءة والصـلاحية للاعستخدام الفوري بو اسطة بريطانيا فى حالة وقوع هجوم مسلح
عمو مية لمناقشة الموضوع و عقدت الجمعية العمومية و التي كان بر أسها محمود سليمان وقدم تقرير ورد فيه (أن هذا المشروع يعني ان مصر ستخسر حوالى إع مليون جنيـًا

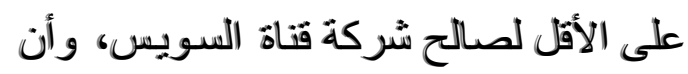
الغين في الصفقة فاحش و الحكومة لم تسمح إلى الآن بإعطاء الأمة حق الاشتر الك معها

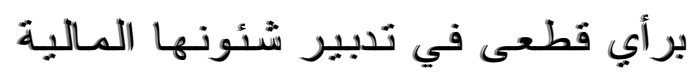

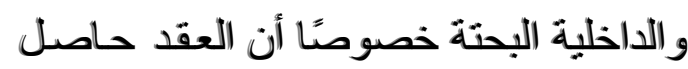

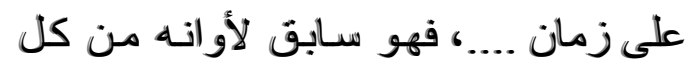
الوجوه و غير مقبول)، واستمرث السيطرة

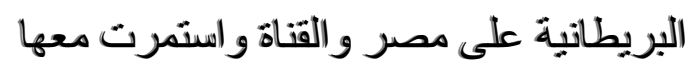
مطالب الوطنيين بالجحلاء حتى تم توقيع

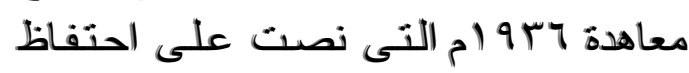
بريطانيا بقاعدة حربية وجوية لها فى منطقة

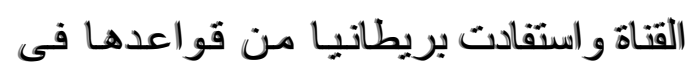


عقد هذه الاتفاقية بين مصر وبريطاتيا أحد

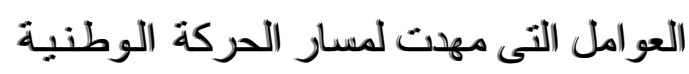

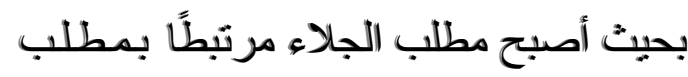
استعادة قناة السويس وأصبحت منظومة واحدة فى برنامج التتظيمات السياسية . فى خـلال الحرب العـالميـة الثثانية

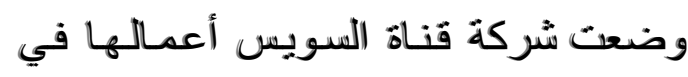
منطقة القناة تحت سيطرة القوات البربطانية ومنعت السفن الألمانية من المرور في القناة.

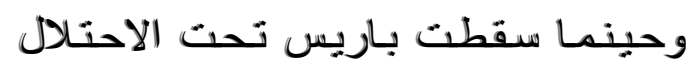
الألماني، ومعها مكاتب الثركة في بـاريس،

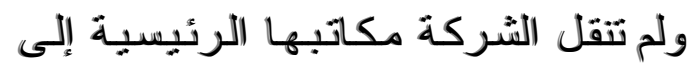

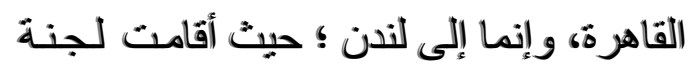
المديرين البريطانيين للإشر اف على أعمال العي 
أهم أسباب فثل العدوان الثثلاثي على مصر

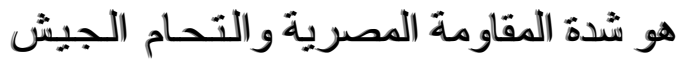
مع الثـب ضد العدوان، وتأييد الاتحـاد السوفيتي لمصر وتهديده بالتدخل العسكري لوقف العدوان ووقوف الثـعوب العربية



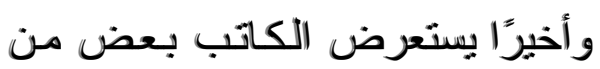
أسماء وشخصيات لهم دور فى شَق القناة بداية من كونها فكرة إلى القناة منها :

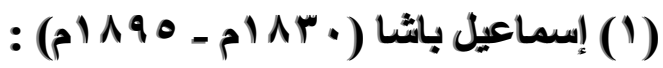

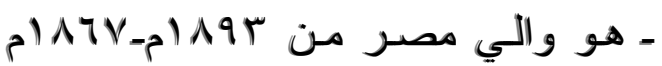

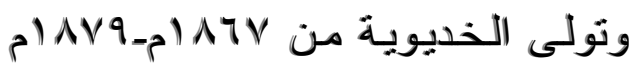
وهو الابن الأكبر لإبر اهيم بـاثنا وحفيد

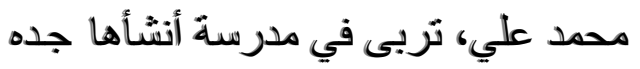
بالقصر العالي، ثم التحق بالبعثة الخامسـة بياريس.

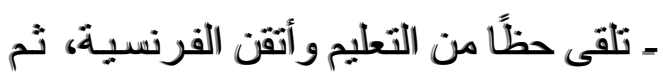

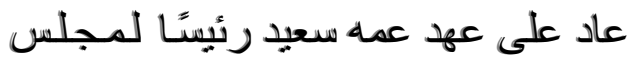
الأحكام.

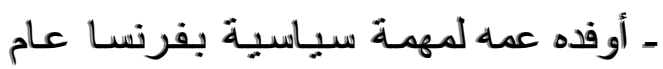
100 (م، صار وليًا للعهد بعد وفاة أخبيه في سنة 100 أم. ـ كاقح تجارة العبيد / الرقيق بالسودان،

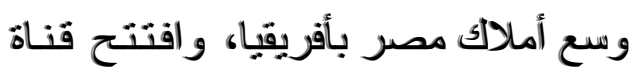

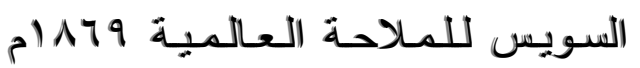
ارتبكت مالية مصر في عهده وباع أسهم مصر في قتاة السويس لانجلترا في ملي م) AVO ـ عزله السلطان عبد الحميد الثانى في يونيو AV9 ام تحت ضغط من انجلتران

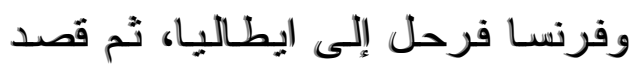

من دولة خارجية على احدى الدول العربية او تركيا مع ضمان حرية الملاحة فى القناة.

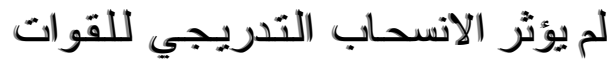

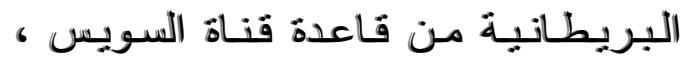
أو إصرار مصر على رفض السماح للسفن فئن

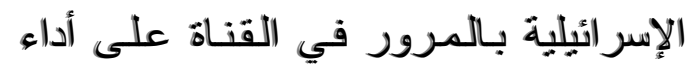
الثركة بل إن أخطر خلاف بين الجـانبين

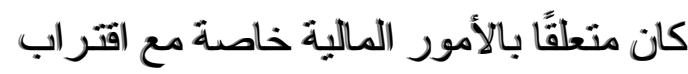

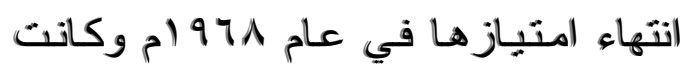
الحكومـة المصريـة تريد من الثركة أنسان تستمر الحتياطياتها فى مصر غير أن الشركة شعرت أن ذلك سوف يؤدي إلى فقدانها

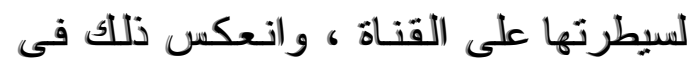
رفض مصر سحب البنك الدولى عرضه وانه

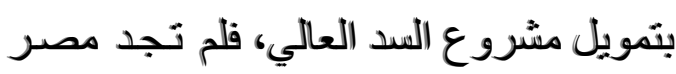

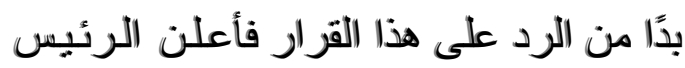

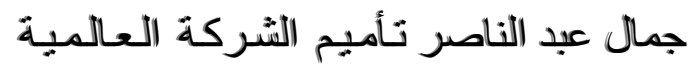
البحرية لقناة السويس فى خطاب ألقاه في (Tr يوليو 907 (م)، ووصف شركة القناة

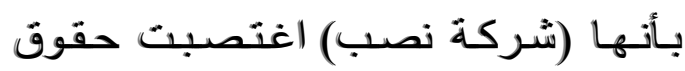

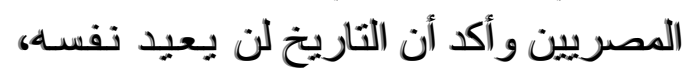

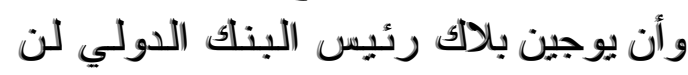

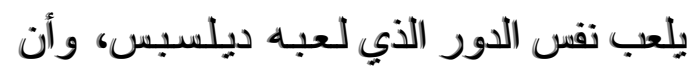
مصر سوف تبني السد العالى؛ للالك ستقوم

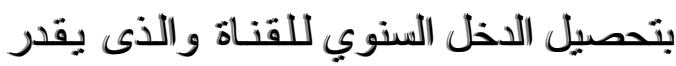
بمائة مليون دو لارًا.

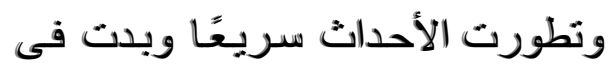
الأفق نيران الحرب وخطة لغزو مصر

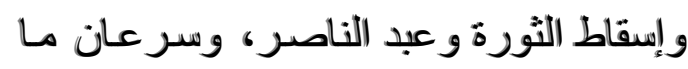
اتضحت معالمها في العدوان الثثلاثي الذي وعي وني

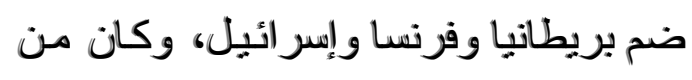


أمام قناصل الدول الأجنبية وأعلن انه عهد إلى ديلمبس بتكوين شركة تتولى الئ حفر القناة.

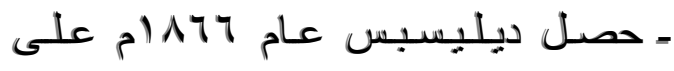
التصديق الشرعي لامنياز القناة وسيق

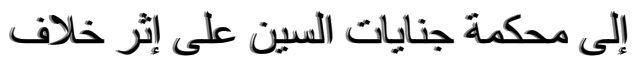
بينه وبين الإنجليز وقضت المنابت المحمة عليه

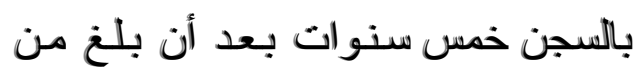

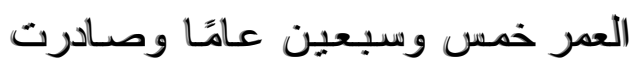

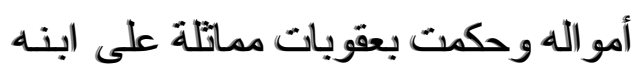
شارل أيضًا ونقذ الحكم على شـارل، أمـا ديلسبس فقد أعفي من الحكم بحكم محكمة التقض القرنسية.

\section{: (r) مشهور أحمد مشهور}

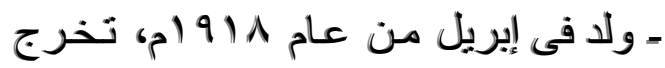
من كلية أركان حرب القوات المسلحة المصرية وكلية الهندسة بجامعة القاهرة


بوزارة النقل وإلتحق بسلاح المهـندسين

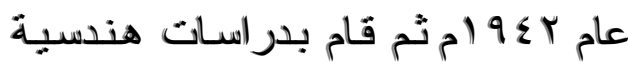
بسـلاح المـهندسين البريطـاتي عـام

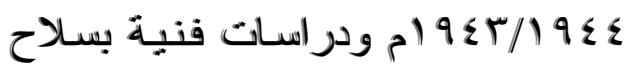
المهندسين بـالو لايـات المتحدة بعدات بعدات

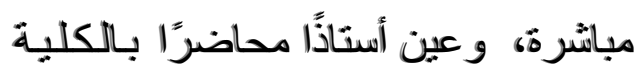
الحربية وكلية أركان حرب في الفترة من . $28 / 190 r$ - بدأ مشّواره في هينَّة قنـاة السـويس المصرية كعضو مجلس إدارة فى عام هام

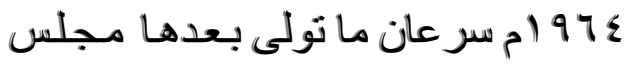
إدارة الهيئة والعضو المنتدب بها في عام 970 (م، ساهم فى تطوير وإدارة هيئة
الأستانة فى عام A10 ا م حتى توفي قدفن

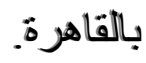

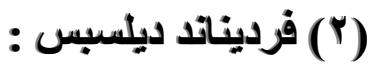

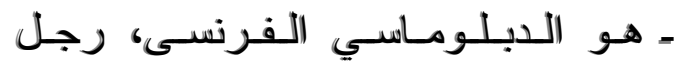
استعماري أر اد أن يجعل من مشروع قناة السويس أداة لتمكين فرنسـا من احتـلال مصر و السيطرة على الثرق.

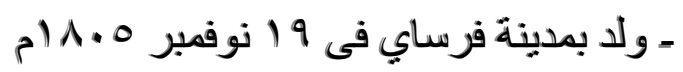

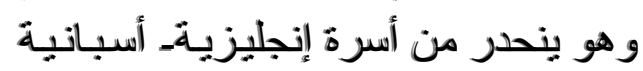

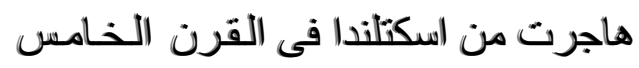
عشر واسنقرت في فرنسـا، كان مـا ثيو

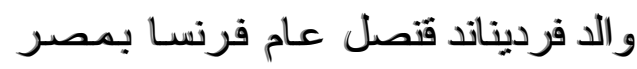



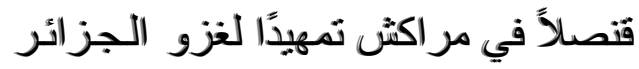

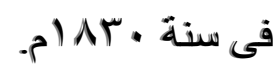
- في السادسة من عمره استطاع فرديناند أن يستولي على قلب محمد علي لأنـه ابن

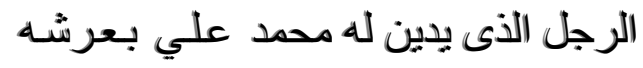

$$
\text { ومجده. }
$$

- عكف ديلسبس على در اسة كل مـا يتصل بمشروع قناة السويس ، وكانت التقارير و المذكرة الخاصة بمشروع الناة القناة التى ولى

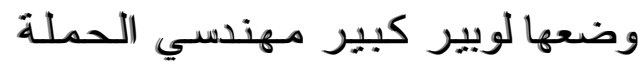

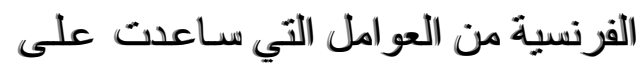

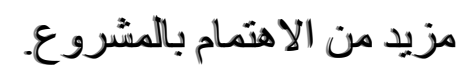

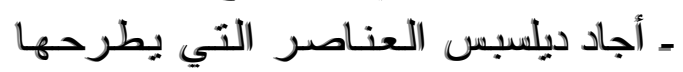

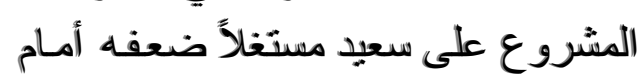
المدح والإطراء على ذاته ؛ حيث كانـا يستهويانه وماكان منه إلا أن وافق على دالى المشروع وفي حفل كبير في القلعة أعلن

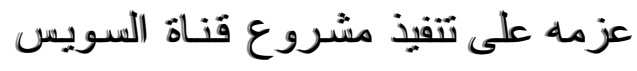


(†) المهندس/ محمود يونسس : - محمود يونس أحمد من مواليد القاهرة

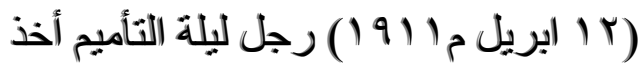
على عاتقه تنفيذ قرار الرئيس جمال عبد

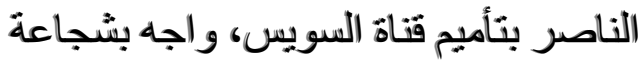
أزمة إضراب المرشُدين الأجانب عن

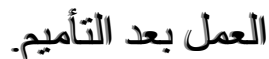

ـ عمل كرئيس مجلس إدارة هيئة قناة السويس وأول عضو منتدب لـها عـام 907 ام وعمل نـائبًا لرئيس الوزيس الوزراء لشئون التقل والمواصلات، وعمل وزيرًا

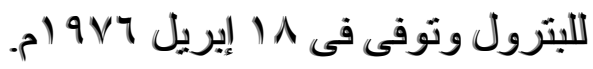
- نجح المؤلف فى التأكيد على أن قصة حفر فئر وتأميم القناة هي قصنة كفاح ونضـال للشعب المصري ضد الاستعمار والحفاظ

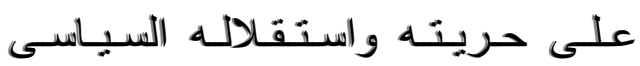
والاقتصادي وهذا جاء نتاج لثورة سب وان

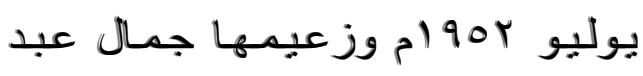
الناصر صاحب قرار التأميم. - إن هذا الكتاب يقيد الباحثين الذين يهتمـون بـالتاريخ المصري خـاصـة والتـاريخ


بالشخصيات التاريخية البارزة التي لـانها دور هام في التاريخ المصري .

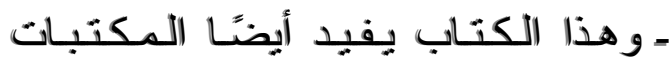
المتخصصة في التاريخ ويثري مقتنياتها الخاصة بتاريخ مصر الحديث بجاتب المكتبات العامة.
قناة السويس في فترة من القتر ات الصعبة

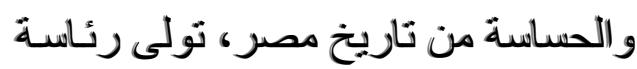
هيئة فناة السويس من يوم ع أ أكتوبر

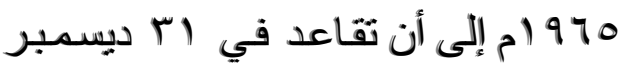

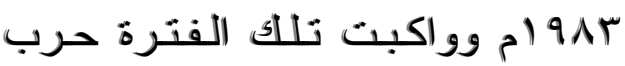
V 9 ام التى احتلث فيها سينـاء و أغلق الممر الملاحى لقناة السويس حتى نصر احتى أكتوبر من عام س 9 ام انتخب عضواً بمجلس الشُعب عن محاقظة الإسماعيلية

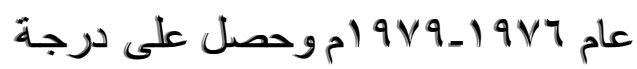

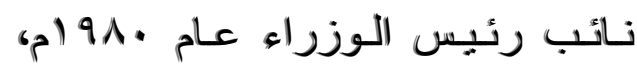
وحصد على عدد من الأوسمة والنياشين

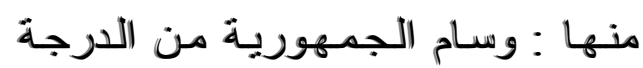

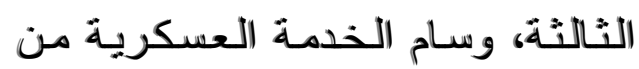

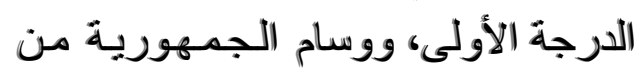
الدرجة الأولى ، ووسام التحرير ووسيام التجهي قلسطين.

\section{(ع) محمد عزت عادل (رائد تطوير القتاة):}

ـ محمد عزت عادل من مواليد محافظة

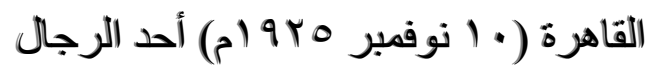

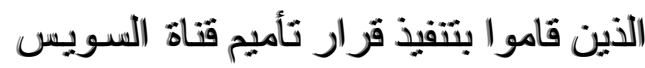
عام 907 (م، رئيس مجلس إدارة هيئة قناة السويس سايقًا.

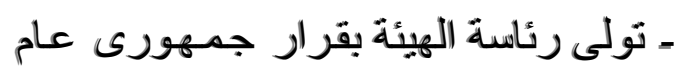

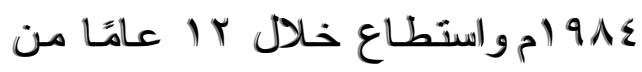
رئاسته لقتاة السويس أن يرفع إيراد القناة

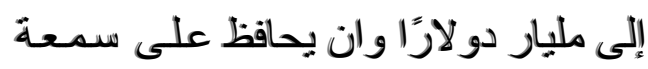
هيئة قناة السويس الدولية ونال عدة أوسمة

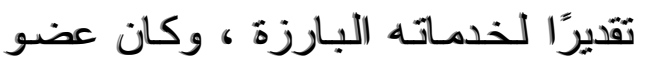

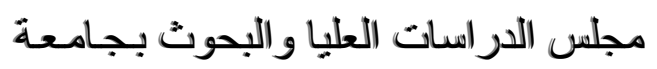
قناة السويس. 